\title{
BMJ Open Effectiveness of varenicline and counselling for smoking cessation in an observational cohort study in China
}

\author{
Bin Jiang, ${ }^{1}$ Yao He, ${ }^{2}$ Fang Zuo, ${ }^{1}$ Lei Wu, ${ }^{2}$ Qing-Hui Liu, ${ }^{3}$ Li Zhang, ${ }^{4}$ \\ Chang-Xi Zhou, ${ }^{3} \mathrm{~K}$ K Cheng, ${ }^{5}$ Sophia S C Chan, ${ }^{6}$ Tai Hing Lam ${ }^{7}$
}

To cite: Jiang B, He Y, Zuo F, et al. Effectiveness of varenicline and counselling for smoking cessation in an observational cohort study in China. BMJ Open 2016;6: e009381. doi:10.1136/ bmjopen-2015-009381

- Prepublication history for this paper is available online. To view these files please visit the journal online (http://dx.doi.org/10.1136/ bmjopen-2015-009381).

Received 15 July 2015 Revised 4 November 2015 Accepted 14 December 2015

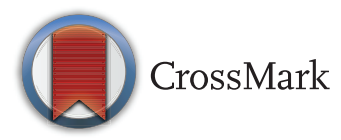

For numbered affiliations see end of article.

Correspondence to Professor Yao He; yhe301@sina.com

\section{ABSTRACT}

Objectives: To evaluate the effectiveness of varenicline for smoking cessation in Chinese smokers in a real world cessation clinic practice.

Design: A prospective observational study.

Setting: Beijing, China.

Participants: A total of 924 smokers (883 men and 41 women) who attended a smoking cessation clinic of a large general hospital were assessed with data from structured questionnaires at baseline and follow-up at 1, 3 and 6 months. Trained physician counsellors provided free individual counselling for all subjects and follow-up interviews with brief counselling. 332 subjects additionally prescribed varenicline according to their own choice were compared with those without varenicline.

Main Outcome Measures: Primary outcomes were self-reported 7-day point prevalence abstinence rate and 3-month continuous abstinence rate at 6-month follow-up. Secondary outcomes were 7-day point prevalence abstinence rates at 1 and 3-month followup, and 1-month continuous abstinence rate at 3-month follow-up.

Results: By intention-to-treat, the 7-day point prevalence abstinence rate with varenicline and counselling at 6 months was significantly higher than counselling only $(37.0 \%$ vs $23.1 \%$; OR, $1.75 ; 95 \% \mathrm{Cl}$ 1.46 to $2.62 ; p=0.001)$. The 3 -month continuous abstinence rate at 6 months was higher with varenicline (33.1\% vs $18.4 \%$; OR, 2.04; $95 \%$ Cl 1.61 to 2.99 ; $\mathrm{p}<0.001)$. Varenicline also showed better secondary outcomes.

Conclusions: Varenicline prescription in the smoking cessation clinic appeared to be effective with doubling of quit rates in Chinese smokers in a real world cessation clinic practice.

Clinical trial registration: NCT01935505; Results.

\section{INTRODUCTION}

Tobacco kills half of long-term smokers and, every year, more than 500 million people worldwide die from tobacco-related diseases. ${ }^{1}$ In 2010, the China National Prevalence Survey found that $52.9 \%$ of men and $2.4 \%$ of

\section{Strengths and limitations of this study}

- There is strong evidence confirming the effectiveness of varenicline on smoking cessation in many randomised controlled trial studies, however, prospective evidence on the effectiveness of varenicline in actual clinical practice, especially with a control group, in Chinese (Asia and other Western countries) in a real world setting is scarce.

- Compared to brief counselling alone, varenicline prescription in the smoking cessation clinic appeared to be effective, with doubling of quit rates in Chinese smokers in a real world cessation clinic practice.

- The study provides, for the first time, information on the effectiveness of different interventions including varenicline and counselling in a real world smoking cessation clinic of a large general hospital in China.

- The quit rate was based on self-report by trained research assistants using a well-constructed and validated questionnaire, it may have limited validity and reliability.

women were current smokers, and $85.6 \%$ current smokers smoked daily. In 2010, there were an estimated 301 million current smokers in China, making this country the largest consumer of tobacco in the world. ${ }^{2}$ But China is only at the early stage of the tobacco epidemic and the burden of disease caused by smoking will increase greatly in the next few decades.

The most effective way of reducing the tobacco toll is smoking cessation. In China, currently approved medications for smoking cessation include nicotine replacement therapy (NRT), bupropion sustained release (SR) and a selective $\alpha 4 \beta 2$ nicotinic acetylcholine receptor partial agonist, varenicline tartrate. Specifically developed for smoking cessation, varenicline first showed superior efficacy versus bupropion $\mathrm{SR}$ and placebo in randomised controlled trials (RCTs) in the West. ${ }^{3}{ }^{4}$ Several RCTs conducted 
later in six Asian countries, including China, also showed that varenicline had greater smoking abstinence rates than placebo. ${ }^{5-7} \mathrm{~A}$ meta-analysis of various nicotine receptor partial agonists (including cytisine, dianicline and varenicline) found that varenicline at standard dose was superior to bupropion SR and placebo as a smoking cessation aid. ${ }^{8}$

While RCTs have excellent internal validity, their external validity is limited, in particular, by their inclusion and exclusion criteria, exclusion of subjects with some diseases, and the additional attention and better adherence of the subjects. The effectiveness in real world practice often appears to be lower. Reports of effectiveness from a real world setting are scarce.

The 1996 China National Survey showed that $71.8 \%$ of smokers did not want to quit smoking, $16.6 \%$ of smokers intended to quit, but had not taken any action, $11.6 \%$ who had smoked daily had quit smoking but relapsed later and only $3.6 \%$ smokers had successfully quit for more than 2 years. ${ }^{9}$ A systematic literature review showed that success rates among smokers who attempt to stop smoking by themselves are low: only $3-5 \%$ at $6-12$ months after initiating a cessation attempt. ${ }^{10}$ The 2010 Global Adult Tobacco Survey in China showed that, among those who had attempted to quit during the past 12 months, $91.8 \%$ did not use any method to assist smoking cessation. Only $33.9 \%$ of smokers who had seen a doctor in the past year had cessation advice from the doctor. ${ }^{2}$

Although there is evidence on the effectiveness of varenicline in Chinese people in an RCT ${ }^{5}$ and in an observational study, ${ }^{11}$ we found no report on the effectiveness of varenicline in actual clinical practice with a Chinese control group in a real world setting. The aim of the present study was to assess the effectiveness of varenicline for smoking cessation in a real world practice of a smoking cessation clinic (SCG) in Beijing, China.

\section{METHODS}

\section{Study setting and participants}

A SCC in the outpatient department of PLA General Hospital was set up in October 2008 and has continued to the present. The hospital has about 12000 outpatients per day. The clinic has 4 weekday evening sessions (Monday to Thursday from 6:30 to 9:00 pm).

Initially, five part time physicians were trained and qualified as smoking cessation counsellors after passing an examination, similarly to a previous procedure reported in Hong Kong. ${ }^{12}$ These physicians provide free individual counselling to all participants. Exhaled air carbon monoxide test is also tested at no charge.

In our study, the subjects were current smokers who were local or non-local residents from different parts of the country. They came to the SCC directly or called the SCC booking hotline to make an appointment and first visited the SCC from 28 October 2008 to 31 March 2014. All subjects were willing to quit smoking and signed an informed consent form. At the first visit, those who were unwilling to participate in the follow-up survey were excluded. The details of the set-up and operation of the SCC has been described previously. ${ }^{13}$

Eight hundred and eighty-three men and 41 women, aged 17-79 years, who were smoking one or more cigarettes daily and wanted to stop smoking, were eligible. Those using bupropion SR $(n=131)$ and NRT $(n=21)$ were excluded. Of the 924 participants included, 182 $(21 \%)$ were lost to follow-up at 6 months (figure 1).

\section{Data collection}

The baseline and follow-up questionnaires were developed with reference to the Hong Kong clinic, and other widely used and validated questionnaires, with about 40 closed-ended questions. ${ }^{12}{ }^{14}$ The baseline questionnaire, completed at the first SCC visit, included demographic characteristics such as age, sex, marital status and education level, perceived health status in the past 3 months and smoking history such as level of smoking, pack-years of smoking and the number of prior quit attempts. The level of nicotine addiction was based on the Fagerström Questionnaire. ${ }^{15}$ Motivation of quitting was measured by asking the smokers how important it was for them to quit smoking, on a scale of 1-100 (1 being least important and 100 being most important). Responses were categorised into more important (scoring above the mean) and less important (scoring below the mean). Similar questions were asked to measure perceived confidence and difficulty in quitting. ${ }^{14} 16$

Other information collected included tobacco-related diseases, history of drug, alcohol or physical activity and willingness to pay for quitting. Exhaled air carbon monoxide level at first visit was measured using the 'Bedfont Micro II Smokerlizer'. Height, weight, blood pressure, and waist and hip circumference, were also recorded.

\section{Interventions}

At the first visit, the interview for the baseline questionnaire was conducted face-to-face, and the process allowed the smokers to reflect on their smoking and quitting experiences, and gave the physician a better understanding of the smokers, to guide the counselling. Smoking cessation counselling for 30-40 min was then provided for all smokers.

Counselling clues were devised from the needs of individual smokers, their smoking status, physical dependency level and tobacco related diseases. The physician adopted a non-directive approach based on the Prochaska transtheoretical model ${ }^{17}$ It included the five 'A's' (ask, advise, assess, assist and arrange), assessing the stage of readiness in quitting smoking, strengthening smokers' motivation to quit smoking using the five ' $R$ 's' (relevance, risks, rewards, roadblocks and repetition) approach. The dangers of smoking as well as the impact on the smokers' existing disease and the benefits of quitting were reviewed, and the smokers' knowledge and potential barriers to smoking cessation were assessed. Behavioural self-management techniques to prevent 


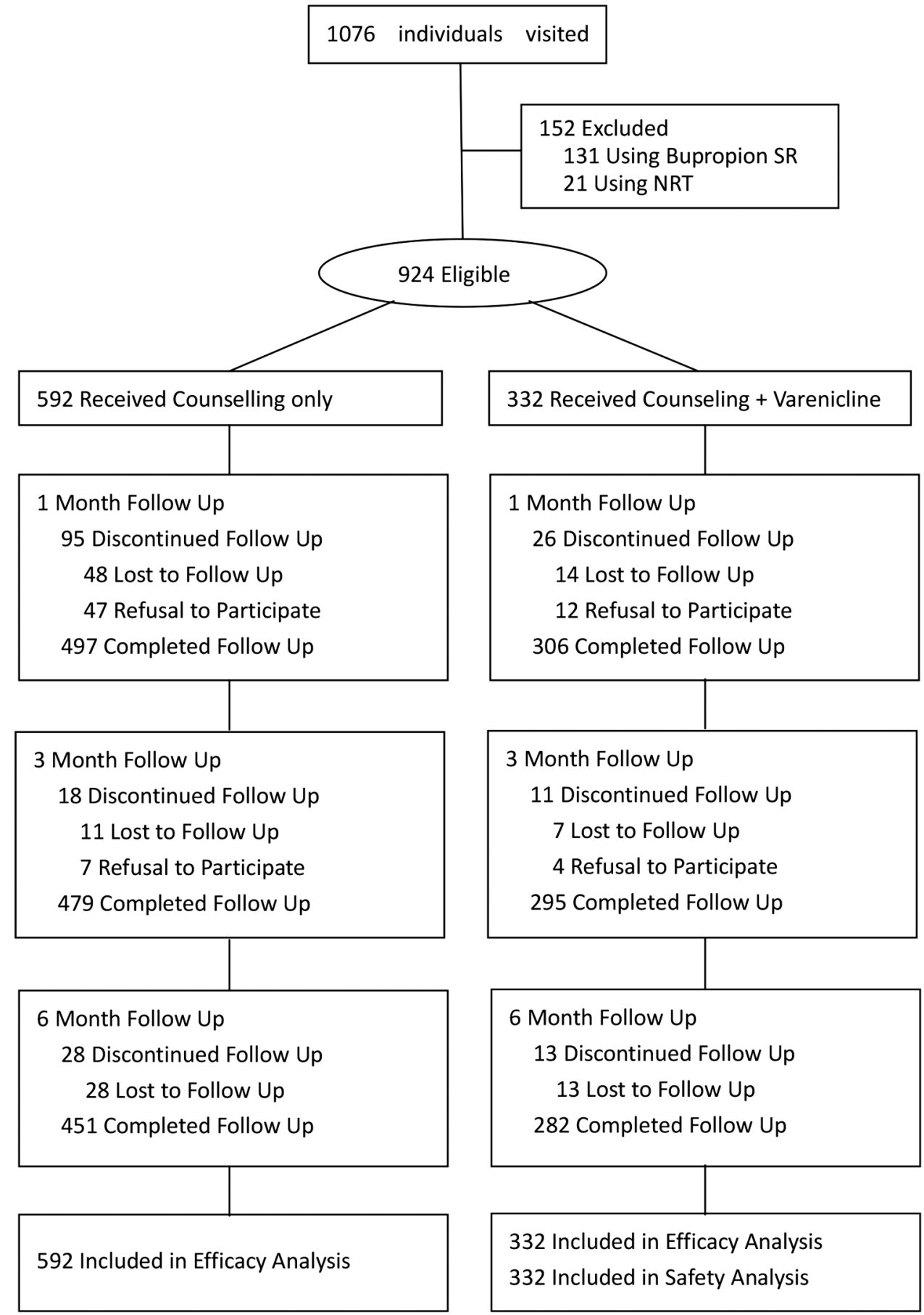

Figure 1 Subject disposition. NRT, nicotine replacement therapy.

relapse, and methods to overcome physiological craving, psychological dependence and social-cultural factors with tobacco dependency, were also discussed.

The final step described how to quit smoking. Communication between physicians and smokers is necessary in order to develop a cessation programme to fit each smoker. At the early stage (about 2 years) of the SCC, the physicians would recommend medications for smokers who smoked heavily, with severe nicotine dependence and lack of confidence in quitting. Based on the early experience of using varenicline, the physicians had a better understanding of its cessation efficiency, and would recommend varenicline for each smoker as an aid to smoking cessation. The price of the Starting Box, which is used for 2 weeks, is 263 RMB (US $\$ 1=6.25 \mathrm{RMB}$ ), and the price of the Continuing Box, also used for 2 weeks, is 352 RMB.

The cost of the full course (12 weeks) treatment is about 2000 RMB (1 Starting Box +5 Continuing Boxes). Since smoking cessation is not covered by statutory health insurance in China, the cost of the drugs used in our study was paid for by the smokers. Due to the high 
price of varenicline, some smokers declined it. In the SCC, the physician would respect the choice of the smoker. Thus, the smokers were divided into two groups according to individual choices: those who received counselling and varenicline were categorised into the varenicline group, and the others who received counselling only were the comparison counselling-only group.

Medications were prescribed at the first visit. Smokers who started treatment with varenicline were instructed to take their first dose the following day. Varenicline was titrated to full dosage over 1 week $(0.5 \mathrm{mg}$ once daily for days $1-3 ; 0.5 \mathrm{mg}$ twice a day for days $4-7$; then $1 \mathrm{mg}$ twice a day thereafter). Treatment duration was not mandatory and depended on the choice of the smoker.

\section{Follow-up}

Follow-up assessment was made at 1,3 and 6 months after the first visit. Only a minority of smokers $(<5 \%)$ returned to the SCC at the scheduled time for follow-up. Some subjects receiving varenicline would visit the SCC irregularly for the prescription, and brief face-to-face personalised counselling (20-30 $\mathrm{min}$ ) was given at each visit. Those who did not return were followed up over the telephone by physicians or by a specially trained counsellor, with brief telephone counselling (20$30 \mathrm{~min}$ ) for each subject.

The follow-up questionnaires were similar at 1, 3 and 6 months, and were shorter than the baseline version. The following information was collected: self-reported health status, smoking status, tobacco consumption, whether having quit or not, quit attempts, withdrawal symptoms, drug adverse effects and the biggest obstacle to quitting.

\section{Outcomes}

The primary outcomes were 7-day point prevalence rate abstinence and 3-month continuous abstinence rate (CAR) at 6-month follow-up. The secondary outcomes were 7-day abstinence point prevalence rates at 1 month and 3-month follow-up, respectively, as well as 1-month CAR at 3-month follow-up. Smokers who had quit were assessed by asking whether they had smoked any cigarette (a whole cigarette or a puff) during the past 7 days at 1-month, 3-month and 6-month follow-up (point prevalence quit rate), and continuous abstinence for 1 month or 3 months at 3-month and 6-month follow-up (CAR).

The 7-day point abstinence was used as the main outcome measure based on the US Clinical Practice Guideline. ${ }^{18}$ Those who answered 'no' were defined as quitters, with no biochemical validation.

All self-reported adverse events and safety data were documented. For those who had severe side effects, the physicians would instruct them to reduce the dosage or stop the medication.

\section{Statistical analysis}

The data were analysed using Statistical Package for Social Sciences (SPSS) for Windows V.19.0. The baseline characteristics of smokers were described using descriptive statistics. The prevalence of quitters by different baseline factors was compared with $\chi^{2}$ test or Fisher's exact test. Logistic regression modelling was used to identify independent predictors for quitting (by enter method) and to estimate adjusted ORs and 95\% CIs. A p value of $<0.05$ (two tailed) was considered statistically significant. All 924 eligible smokers were included in the analysis by intention-to-treat, and those who had reached the follow-up time but could not be contacted were considered as non-quitters.

\section{RESULTS}

\section{Subject disposition}

Of 1076 smokers who visited the SCC from 28 October 2008 to 31 March 2014, 924 were eligible and included (figure 1). Of these subjects, $61 \%(562 / 924)$ were nonresidents, and the follow-up was carried out mainly by telephone. The 6-month follow-up rate was $76 \%$ (451/592) for counselling, and $88 \%$ (292/332) for varenicline.

Overall, $95 \%$ of the subjects were men and the mean age was 41 years $(\mathrm{SD}=10.6$ years). Varenicline was prescribed to $332(36 \%)$ subjects. Table 1 shows that the varenicline group consumed more cigarettes per day $(p<0.001)$, had a higher Fagerström score $(p<0.001)$ and had made more past quit attempts $(p=0.014)$. There were no significant differences in age, gender, education, the age of the subject when he/she began smoking and number of years of smoking.

\section{Effectiveness}

At 1-month, 3-month and 6-month follow-up, the selfreported 7-day point prevalence abstinence rates and CARs were significantly higher in the varenicline plus counselling group than in the counselling-only group.

The primary outcomes at 6-month follow-up are shown in figure 2. The 7-day point prevalence abstinence rate with varenicline was significantly higher than that of counselling only: $37.0 \%$ versus $23.1 \%$ (OR, 1.96; 95\% CI 1.46 to 2.62; $\mathrm{p}<0.001)$. Also, the 3-month CAR with varenicline was higher, $33.1 \%$ versus $18.4 \%$ (OR, 2.20; $95 \%$ CI 1.61 to $2.99 ; \mathrm{p}<0.001$ ).

The secondary outcomes are shown in table 2. The 7-day point prevalence abstinence rates with varenicline were all greater than those of counselling only: $40.1 \%$ versus $18.6 \%$ ( $\mathrm{OR}, 2.93 ; 95 \%$ CI 2.17 to 3.96 ; $\mathrm{p}<0.001$ ) at 1 month, and $38.0 \%$ versus $22.6 \%$ (OR, 2.01; 95\% CI 1.56 to $2.80 ; \mathrm{p}<0.001)$ at 3 months. The continuous 1-month quit rate at 3 months was also higher: $36.1 \%$ versus $18.4 \%$ (OR, $2.51 ; 95 \%$ CI 1.85 to 3.40 ).

Of 332 subjects who were prescribed varenicline, $52 \%$ reported that they had used varenicline for less than 4 weeks, $40 \%$ for $4-8$ weeks and $8 \%$ for 9 weeks or more. Table 3 shows that the 3-month CAR at 6 months showed an increasing but nonsignificant trend with the duration of drug use ( $p$ for trend $=0.085$ ). Using varenicline for 9 weeks or more showed much higher 3-month CAR with marginal statistical significance. 
Table 1 Baseline demographic characteristics and smoking history of study participants, by counselling group and counselling+varenicline group

\begin{tabular}{|c|c|c|c|}
\hline & Counselling $(n=592)$ & Counselling+varenicline $(n=332)$ & p Value \\
\hline Age, mean (SD), years & $41.2 \pm 11.2$ & $41.3 \pm 9.8$ & 0.898 \\
\hline \multicolumn{4}{|l|}{ Gender, Number (\%) } \\
\hline Male & 568 (95.9) & $315(94.9)$ & \multirow[t]{2}{*}{0.506} \\
\hline Female & $24(4.1)$ & $17(5.1)$ & \\
\hline \multicolumn{4}{|l|}{ Education, Number (\%) } \\
\hline High school and below & $263(44.4)$ & $146(44.0)$ & \multirow[t]{2}{*}{0.945} \\
\hline College and above & $329(55.6)$ & $186(56.0)$ & \\
\hline Age began smoking, mean (SD) & $19.4 \pm 5.2$ & $19.4 \pm 4.4$ & 0.953 \\
\hline Number of years smoked, mean (SD) & $21.4 \pm 10.7$ & $21.3 \pm 9.7$ & 0.864 \\
\hline $\begin{array}{l}\text { Number of cigarettes/day over past } 1 \text { month, } \\
\text { mean (SD) })^{\star \star}\end{array}$ & $20.4 \pm 11.2$ & $22.2 \pm 11.9$ & 0.017 \\
\hline Fagerström score†, mean (SD) & $5.1 \pm 2.5$ & $6.0 \pm 2.5$ & $<0.001$ \\
\hline$\geq 1$ previous quit attempt, $n(\%)$ & $441(74.5)$ & $269(81.0)$ & 0.028 \\
\hline Age, mean (SD), years & $41.2 \pm 11.2$ & $41.3 \pm 9.8$ & 0.90 \\
\hline \multicolumn{4}{|l|}{ Gender, n (\%) } \\
\hline Male & $568(95.9)$ & $315(94.9)$ & \multirow[t]{2}{*}{0.51} \\
\hline Female & $24(4.1)$ & $17(5.1)$ & \\
\hline \multicolumn{4}{|l|}{ Education, n (\%) } \\
\hline High school and below & $263(44.4)$ & $146(44.0)$ & \multirow[t]{2}{*}{0.96} \\
\hline College and above & $329(55.6)$ & $186(56.0)$ & \\
\hline Age began smoking, mean (SD) & $19.4 \pm 5.2$ & $19.4 \pm 4.4$ & 0.95 \\
\hline No of years smoked, mean (SD) & $21.4 \pm 10.7$ & $21.3 \pm 9.7$ & 0.86 \\
\hline No of cigarettes/day over past 1 month, mean $(\mathrm{SD})^{\star *}$ & $20.4 \pm 11.2$ & $22.2 \pm 11.9$ & $<0.05$ \\
\hline Fagerström score†, mean (SD) ${ }^{\star}$ & $5.1 \pm 2.5$ & $6.0 \pm 2.5$ & $<0.001$ \\
\hline$\geq 1$ previous quit attempt, No $(\%)^{\star \star}$ & $441(74.5)$ & $269(81.0)$ & $<0.05$ \\
\hline
\end{tabular}

\section{Safety and tolerability}

Throughout the observation period, varenicline was safe and generally well tolerated. Among the 332 users, $24 \%$ (95\% CI $20 \%$ to $29 \%$ ) reported adverse events or side effects (table 4). The most frequent were gastrointestinal

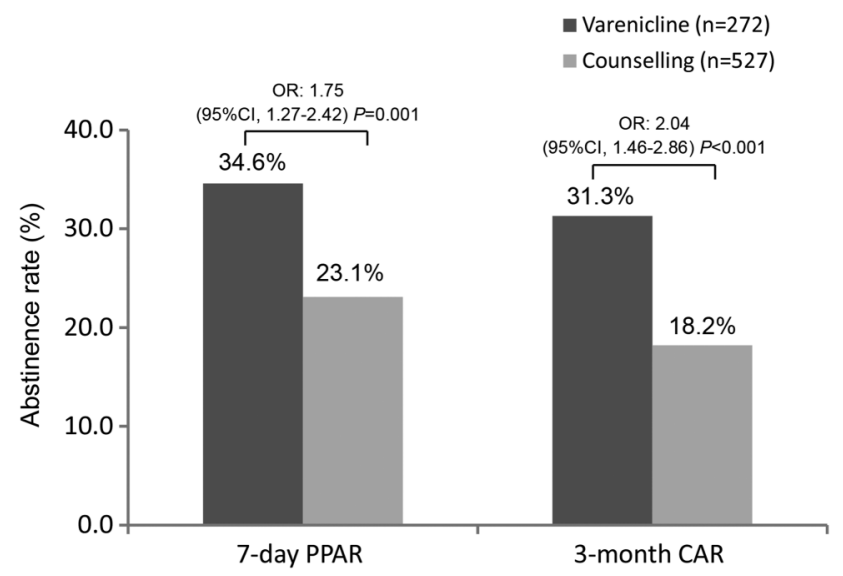

Figure 2 Primary outcomes at 6-month follow-up for 7-day point prevalence abstinence rate (7-day PPAR) and 3-month continuous abstinence rate (3-month CAR). CI OR. CAR, continuous abstinence rate; PPAR, point prevalence abstinence rate. disorders (12.7\%), psychiatric disorders (2.7\%: all were sleep disorders), nervous system disorders (3.3\%: dizziness) and cardiovascular system disorders (2.4\%: palpitation). For gastrointestinal disorders, nausea was the most commonly reported $(9.6 \%)$, followed by flatulence $(2.4 \%)$. The nausea was mostly mild to moderate and diminished over time. No deaths occurred during the treatment and follow-up. Five single serious adverse events $(1.5 \%)$ were recorded during follow-up: severe nausea in 3 subjects and dizziness in 2 subjects. Twenty-six $(7.8 \%)$ users discontinued quitting and 15 $(4.5 \%)$ reduced the dose of varenicline due to adverse events.

\section{Predictors of quitting}

At baseline, 18 factors were chosen in the analysis of predictors of quitting, including demographic characteristics, tobacco use-related factors and varenicline. Demographic characteristics included age, gender, marital status, education and household income per month. Tobacco use-related factors included age at initiation of smoking, cigarettes smoked daily, on average, number of years of smoking, CO level, number of past quit attempts, length of abstinence in the last quit attempt, stage of readiness in quitting, perceived importance, perceived difficulty and perceived confidence in 
Table 2 Secondary outcomes of 7-day PPAR and 1-month CAR at 1-month and 3-month follow-up $(n=924)$

\begin{tabular}{|c|c|c|c|}
\hline Follow-up & Quitting rates \% (n) & OR (95\% Cl) & p Value \\
\hline \multicolumn{4}{|c|}{ 7-day PPAR at 1 month } \\
\hline Varenicline & $40.1(133 / 332)$ & 2.93 (2.17 to 3.96$)$ & \multirow{2}{*}{$<0.001$} \\
\hline Counselling & $18.6(110 / 592)$ & 1.00 & \\
\hline \multicolumn{4}{|c|}{ 7-day PPAR at 3-month } \\
\hline Varenicline & $38.0(126 / 332)$ & 2.01 (1.56 to 2.80$)$ & \multirow[t]{2}{*}{$<0.001$} \\
\hline Counselling & $22.6(134 / 592)$ & 1.00 & \\
\hline \multicolumn{4}{|c|}{ 1-month CAR at 3-month } \\
\hline Varenicline & $36.1(120 / 332)$ & $2.51(1.85$ to 3.40$)$ & \multirow[t]{2}{*}{$<0.001$} \\
\hline Counselling & $18.4(109 / 592)$ & 1.00 & \\
\hline
\end{tabular}

quitting, tobacco related diseases, spouse smoking and drinking.

Table 5 shows that varenicline (OR, 2.1, 95\% CI 1.49 to $2.96, \mathrm{p}<0.001)$, higher daily cigarette consumption and more confidence in quitting were significant independent predictors of quitting. The results were similar after excluding all those who did not return for follow-up.

\section{DISCUSSION}

This is the first real world observational study showing a doubling of smoking abstinence from varenicline in Chinese smokers in a SSC in China. We did not have a sample size calculation but the paper is based on the largest series of such smokers in China.

The strengths of our study were: (1) having a counselling-only comparison group and (2) a longer follow-up period of 6 months.

Few studies have examined the effect of varenicline on smoking cessation in a real world practice in Mainland China, Hong Kong and Taiwan. In China, Liang et $a l^{19}$ observed 25 subjects in their clinical practice and reported that the abstinence rate continuously for 4 weeks (9-12 weeks) with varenicline was $48 \%$ at 12 weeks of follow-up, and that the CARs for longer (8-12 weeks) treatment times were higher than those for shorter $(<8$ weeks $)$ treatment times $(p=0.027)$. But there was no comparison or control group.
Studies of the effectiveness of varenicline in real world clinics were scarce, compared to RCTs. Dhelaria et $a l^{20}$ conducted a retrospective cohort study at 2 urban academic health centres in the USA, and found that $10.2 \%$ patients who received varenicline and had at least one follow-up visit maintained abstinence through 1 year at the 52-week follow-up. Assuming those who had no follow-up had not quit, the overall quit rate was only $6.4 \%$. Blak et al also conducted a retrospective study in a UK general practice setting. They identified varenicline users from records in The Health Improvement Network database, and sent a questionnaire to patients who commenced smoking cessation treatment close to the selection date $(6$ months prior to the date of questionnaire dispatch), and the overall 7-day point prevalence abstinence rate was $49.5 \%$ (after 6 months since starting varenicline). But this study had only 193 responses and a low response rate of $26.4 \% .^{21}$ In an inter-Asian 12-week, prospective, observational, non-comparative varenicline trial, the proportion of subjects in China with an abstinence status of 'Quit' before week 12 was $57.1 \%$ (95\% CI $53.55 \%$ to $60.65 \%) .{ }^{11}$ A varenicline phase IV trial in Germany showed that the 7-day abstinence rate between weeks 11 and 12 was $71.1 \%$ (95\% CI $68.5 \%$ to $73.7 \%) .{ }^{22}$ In another 12 -week, prospective, observational, non-comparative trial of varenicline in four European countries (Belgium, Greece, Hungary and Slovenia), the 7-day point prevalence abstinence rate at

\begin{tabular}{|c|c|c|c|c|c|c|}
\hline Duration of varenicline & Quitting rates \% (n) & OR $(95 \% \mathrm{Cl})$ & p Value* & $p$ for Trend & OR $(95 \% \mathrm{Cl})$ & p Valuef \\
\hline \multicolumn{7}{|l|}{ 7-day PPAR } \\
\hline$\geq 9$ weeks & $56.0(14 / 25)$ & $2.48(1.06$ to 5.80$)$ & 0.036 & 0.067 & 2.11 (0.89 to 5.01$)$ & 0.090 \\
\hline $4-8$ weeks & $40.7(50 / 133)$ & 1.17 (0.73 to 1.88$)$ & 0.504 & & 1.00 & \\
\hline$<4$ weeks & $33.9(59 / 174)$ & 1.00 & & & & \\
\hline \multicolumn{7}{|l|}{ 3-month CAR } \\
\hline$\geq 9$ weeks & $48.0(12 / 25)$ & 2.17 (0.93 to 5.06$)$ & 0.074 & 0.085 & 1.75 (0.74 to 4.13$)$ & 0.205 \\
\hline $4-8$ weeks & $34.6(46 / 133)$ & $1.24(0.77$ to 2.01$)$ & 0.382 & & 1.00 & \\
\hline$<4$ weeks & $29.9(52 / 174)$ & 1.00 & & & & \\
\hline
\end{tabular}


Table 4 All-causality, treatment-emergent adverse events (AE) among subjects receiving varenicline

\begin{tabular}{lc}
\hline & $\begin{array}{c}\text { Varenicline } \\
(\mathbf{n}=332) \\
\text { No (\%) }\end{array}$ \\
\hline Any adverse event & $80(24.1)$ \\
Most frequent AE & \\
Gastrointestinal disorders & $42(12.7)$ \\
$\quad$ Nausea & $32(9.6)$ \\
Dry mouth & $1(0.3)$ \\
Flatulence & $8(2.4)$ \\
$\quad$ Diarrhoea & $1(0.3)$ \\
Psychiatric disorders & $9(2.7)$ \\
$\quad$ Abnormal dreams & $2(0.3)$ \\
Sleep disorder & $2(0.3)$ \\
Insomnia & $5(1.5)$ \\
Nervous system disorders & \\
$\quad$ Dizziness & $9(3.3)$ \\
Cardiovascular system disorders & \\
$\quad$ Palpitation & $8(2.4)$ \\
Respiratory system disorders & \\
$\quad$ Cough & $2(0.6)$ \\
General disorders & \\
Itching & $7(2.1)$ \\
Serious adverse events & $5(1.5)$ \\
Quitting discontinuation due to AE & $15(4.5)$ \\
Dose reduction or temporary discontinuation \\
due to AE
\end{tabular}

week 12 was $64.6 \%(95 \%$ CI $60.1 \%$ to $68.3 \%) .{ }^{23}$ All the quit rates were based on self reporting only and with short follow-up. None of the studies had a control or comparison group with no varenicline. Our quit rate in motivated smokers seeking help was lower than those mentioned above but could be higher than those in the community who did not seek help.

Of the papers cited above, the latter four, which had very high quit rate, were planned and sponsored by Pfizer Inc. ${ }^{11-23}$ In the observational trial conducted in China, the 7-day quit rate over a 7-day period was $57.1 \%$, but the quit rates of some subjects were assessed with less than 12 weeks of follow-up. ${ }^{11}$ In our study, the 7-day point prevalence abstinence rate with varenicline reached $38.0 \%$ at 3-month follow-up, which appeared to be lower, but our data were all collected at 3-month follow-up. In addition, these observational studies sponsored by Pfizer had only followed up for 12 weeks, we had a longer follow-up of 6 months. The 7-day point prevalence abstinence rate and 3-month CAR was $37.0 \%$ and $33.1 \%$, respectively, at 6-month follow-up, both significantly higher than those of counselling.

There were many RCTs confirming the effectiveness of varenicline. A meta-analysis by Cahill et $a l^{8}$ included RCTs that compared the treatment drug with placebo, excluding trials with less than 6 months of follow-up. They concluded that varenicline at standard dose increased long-term smoking cessation by two fold. The pooled RR for continuous or sustained abstinence at 6 months or longer for varenicline at standard dosage versus placebo was 2.27 (95\% CI 2.02 to 2.55 ; 14 trials, 6166 people). At lower or variable doses, the RR was 2.09 (95\% CI 1.56 to $2.78 ; 4$ trials, 1272 people). In the present study, the OR for 3-month continuous abstinence at 6 months for varenicline versus counselling was 2.04, which was similar to that above pooled RR.

Compared to the RCT that included Chinese smokers, ${ }^{5}$ our 7-day point prevalence $(63.0 \%$ (week 12) in RCT versus $38.0 \%$ (month 3)) and CARs $(50.3 \%$ (9-12 weeks) in RCT versus $36.1 \%$ (2-3-month)) were substantially lower in a real world clinical practice. Two factors might account for the discrepancy: (1) subjects in RCTs were usually more highly motivated with better adherence and had more attention from the researchers and counsellors; (2) subjects in RCTs received a full course of 12 weeks free, but our subjects were seldom prescribed the full course because of the high cost, and over worries about side effects. In the present study, only $4 \%$ were prescribed varenicline for 9-12 weeks.

In addition to varenicline, we found two independent predictors of quitting: lower daily cigarette consumption and greater confidence in quitting. The former indicates a lower nicotine dependence and has often been found to be an important predictor. $^{24-26}$ The latter suggests that counsellors should aim at enhancing confidence and self efficacy. Future studies should examine whether increased confidence could be a mediator between varenicline prescription and quitting. Education was not a predictor of the use of varenicline. In China, high levels of education do not necessarily relate to high incomes. Moreover, the price of medications is not the only factor that determines the choice of drugs. Many subjects did

Table 5 Summary of logistic regression (enter) model to predict quitting smoking

\begin{tabular}{|c|c|c|}
\hline Independent variables & $\mathrm{OR}^{*}(95 \% \mathrm{Cl})$ & ORt $(95 \% \mathrm{Cl})$ \\
\hline Received varenicline treatment & $2.22(1.60$ to 3.08$) \ddagger$ & $2.10(1.49$ to 2.96$) \ddagger$ \\
\hline More cigarettes smoked on average daily§ & 1.56 (1.12 to 2.18$)$ ๆ & 1.56 (1.10 to 2.21$)$ q \\
\hline More confidence in quitting, per score & 1.49 (1.05 to 2.10$)$ १ & 1.53 (1.07 to 2.20$) 9$ \\
\hline
\end{tabular}


not choose varenicline because of concerns about side effects.

The present study also confirmed that varenicline was safe and generally well tolerated in Chinese smokers. The overall self-reported adverse event rate was $24.1 \%$, which is similar to $28.1 \%$ in the inter-Asian observational study. ${ }^{11}$ Adverse event rate of varenicline in most RCTs was higher: $78.4 \%$ in smokers in the $\mathrm{US},{ }^{3} 77 \%$ in smokers in China, Singapore and Thailand, ${ }^{5} 86.5 \%$ in smokers in Taiwan and Korea, ${ }^{6}$ and $80.1 \%$ in smokers in Japanese. ${ }^{7}$ The lower rate in the present study could be due to the much shorter duration of treatment and/or under-reporting.

Our study had some limitations. First, the subjects of the two groups were not similar. The varenicline group could be more motivated as they were willing to pay the high cost of the drug. Second, because most subjects were not local residents, most of the follow-up was carried out by telephone interview, and the quit rate was based on self-reporting. Third, the duration of medication varied with different and unverified adherence. Fourth, our results were up to 6-month follow-up. We shall continue to follow-up at 1 year and beyond. Finally, the $24 \%$ loss in follow-up rate of the counselling group was significantly higher than the $12 \%$ of the varenicline group $(p=0.013)$. But the results of both 7 -day point prevalence abstinence rate and CAR were similar after excluding all those who did not return for follow-up; only the values of OR were slightly lower and a $p$ value slightly increased. Fifth, our loss to follow-up rate was $21 \%$. Previous varenicline papers showed that $26.4 \%^{21}$ to $29 \%{ }^{27}$ were lost to follow-up. Our intention-to-treat analysis assumed those lost to follow-up had not quit, as most of them had low intention to quit (some came only under pressure from family members, others' intention to quit reduced after going back to their living and working environments, and some relapsed). This group most likely would refuse follow-up by telephone. Hence, the loss to follow-up rate and intention-to-treat analysis should not have affected the results (by over- or underestimating the quit rates) substantially.

The present study is important because it provides, for the first time, information on the effectiveness of different interventions including varenicline and counselling in a real world SSC of a large general hospital in China. Having a counselling group as a comparison group in this study, which was not seen in other observational studies, is a most significant advantage.

Our findings suggest that varenicline should have a major role in smoking cessation in China but its cost is high, and smoking cessation counselling and medications are not covered by statutory health insurance in China. The prescription and use of the drug is extremely low in routine clinical settings and in SSCs. We recommend that the price of the drug be reduced to encourage more physicians to prescribe and more smokers to use varenicline, and that the drug be covered by health insurance.

\section{CONCLUSION}

Compared to brief counselling alone, varenicline prescription with brief counselling in a SSC appeared to be effective, with doubling of quit rates in Chinese smokers in a real world cessation clinic practice in China.

\section{Author affiliations}

${ }^{1}$ Nanlou Faculty of Clinical Medicine, Department of Traditional Chinese Medicine and Acupuncture, Chinese People's Liberation Army General Hospital, Beijing, China

${ }^{2}$ Department of Epidemiology, Institute of Geriatrics, Beijing key laboratory of Aging and Geriatrics, Chinese People's Liberation Army General Hospital, Beijing, China

${ }^{3}$ Nanlou Faculty of Clinical Medicine, Department of Respiration, Chinese People's Liberation Army General Hospital, Beijing, China

${ }^{4}$ Nanlou Faculty of Clinical Medicine, Department of Rehabilitation, Chinese

People's Liberation Army General Hospital, Beijing, China

${ }^{5}$ Public Health, Epidemiology and Biostatistics, University of Birmingham, Birmingham, UK

${ }^{6}$ School of Nursing, School of Public Health, The University of Hong Kong, Hong Kong, China

${ }^{7}$ Department of Community Medicine, School of Public Health and The University of Hong Kong, Hong Kong, China

Acknowledgements The authors thank $L X, J H Z$ and JF for research assistance in the follow-up interviews.

Contributors $\mathrm{YH}, \mathrm{BJ}$ and THL designed the study and analysed the data. BJ, FZ, Q-HL, C-XZ, LZ and LW contributed to data collection and field operations. THL, SSCC and KKC contributed to the setting up of the clinic and design of the interventions, and provided training. $\mathrm{BJ}$ and $\mathrm{YH}$ took final responsibility for the decision to submit for publication.

Funding This study was supported by research grants from the National Natural Science Foundation of China, 81373080; Beijing Municipal Science and Technology Commission, Z121107001012070; Cancer Research UK: Smoking cessation and advocacy training among health professionals in Beijing and Guangzhou, China, C1343/A10155.

Competing interests None declared.

Patient consent Obtained.

Ethics approval This project was approved by the Ethics Committee of the PLA General Hospital in China.

Provenance and peer review Not commissioned; externally peer reviewed.

Data sharing statement No additional data are available.

Open Access This is an Open Access article distributed in accordance with the Creative Commons Attribution Non Commercial (CC BY-NC 4.0) license, which permits others to distribute, remix, adapt, build upon this work noncommercially, and license their derivative works on different terms, provided the original work is properly cited and the use is non-commercial. See: http:// creativecommons.org/licenses/by-nc/4.0/

\section{REFERENCES}

1. Kaleta D, Kozieł A, Miśkiewicz P. MPOWER — strategy for fighting the global tobacco epidemic. Med Pr 2009;60:145-9.

2. Li Q, Hsia J, Yang GH. Prevalence of smoking in China in 2010. N Engl J Med 2011;364:2469-70.

3. Gonzales D, Rennard SI, Nides M, et al. Varenicline, an alpha4beta2 nicotinic acetylcholine receptor partial agonist, versus sustained-release bupropion and placebo for smoking cessation: a randomized controlled trial. JAMA 2006;296:47-55.

4. Jorenby DE, Hays JT, Rigotti NA, et al. Efficacy of varenicline, an alpha4beta2 nicotinic acetylcholine receptor partial agonist, versus placebo or sustained-release bupropion for smoking cessation: a randomized controlled trial. JAMA 2006;296:56-63.

5. Wang C, Xiao D, Chan KP, et al. Varenicline for smoking cessation: A placebo-controlled, randomized study. Respirology 2009;14:384-92. 
6. Tsai ST, Cho HJ, Cheng HS, et al. A randomized, placebo-controlled trial of varenicline, a selective a4b2 nicotinic acetylcholine receptor partial agonist, as a new therapy for smoking cessation in Asian smokers. Clin. Ther 2007;29:1027-39.

7. Nakamura M, Oshima A, Fujimoto $\mathrm{Y}$, et al. Efficacy and tolerability of varenicline, an a4b2 nicotinic acetylcholine receptor partial agonist, in a 12-week, randomized, placebo-controlled, dose-response study with 40-week follow-up for smoking cessation in Japanese smokers. Clin Ther 2007;29:1040-56.

8. Cahill K, Stead LF, Lancaster T. Nicotine receptor partial agonists for smoking cessation. Cochrane Database Syst Rev 2012;4: CD006103.

9. Yang G, Ma J, Chen A, et al. Smoking cessation in China: findings from the 1996 national prevalence survey. Tob Control 2001;10:170-4.

10. Hughes JR, Keely J, Naud S. Shape of the relapse curve and long-term abstinence among untreated smokers. Addiction 2004;99:29-38

11. Wang C, Cho B, Xiao D, et al. Effectiveness and safety of varenicline as an aid to smoking cessation: results of an inter-Asian observational study in real-world clinical practice. Int J Clin Pract 2013;67:469-76.

12. Abdullah AS, Hedley AJ, Chan SS, et al, Hong Kong Council on Smoking and Health Smoking Cessation Health Centre (SCHC) Steering Group. Establishment and evaluation of a smoking cessation clinic in Hong Kong: a model for the future service provider. J Public Health (Oxf) 2004;26:239-44.

13. He Y, Lam TH, Jiang B, et al. Study design and the preliminary results on the modes of smoking cessation in general hospitals. Chin J Epidemiol 2011;32:192-5.

14. Lam TH, Abdullah AS, Chan SS, et al. Adherence to nicotine replacement therapy versus quitting smoking among Chinese smokers: a preliminary investigation. Psychopharmacology (Berl) 2005; $177: 400-8$

15. Fagerstrom KO, Heatherton TF, Kozlowski LT. Nicotine addiction and its assessment. Ear Nose Throat J 1990;69:763-5.
16. Zhu WH, Yang L, Jiang CQ, et al. Characteristics of smokers and predictors of qutting in a smoking cessation clinic in Guangzhou, China. J Public Health (Oxf) 2010;32:267-76.

17. Prochaska JO, Goldstein MG. Process of smoking cessation. Implications for clinicians. Clin Chest Med 1991;12:727-35.

18. Fiore MC. US public health service clinical practice guideline: treating tobacco use and dependence. Respir Care 2000;45:1200-62.

19. Liang $\mathrm{DH}$, Liu $\mathrm{H}$, Wei CZ. Clinical observation of varenicline for smoking cessation. Chin J New Clin Med 2011;4:1161-2.

20. Dhelaria RK, Friderici J, Wu K, et al. Effectiveness of varenicline for smoking cessation at 2 urban academic health centers. Eur $J$ Intern Med 2012;23:461-4.

21. Blak BT, Wilson $\mathrm{K}$, Metcalfe $\mathrm{M}$, et al. Evaluation of varenicline as an aid to smoking cessation in UK general practice-a THIN database study. Curr Med Res Opin 2010;26:861-70.

22. Andreas S, Chenot JF, Diebold R, et al. Effectiveness of Varenicline as an Aid to Smoking Cessation in Primary Care: An Observational Study. Eur Addict Res 2013;19:47-54.

23. Boudrez H, Gratziou C, Messig M, et al. Effectiveness of varenicline as an aid to smoking cessation: Results of an interEuropean observational study. Curr Med Res Opin 2011;27: 769-75.

24. Razavi D, Vandecasteele $\mathrm{H}$, Primo $\mathrm{C}$, et al. Maintaining abstinence from cigarette smoking: effectiveness of group counselling and factors predicting outcome. Eur J Cancer 1999;35:1238-47.

25. Hyland A, Li Q, Bauer JE, et al. Predictors of cessation in a cohort of current and former smokers followed over 13 years. Nicotine Tob Res 2004;6(Suppl 3):S363-9.

26. Hymowitz N, Cummings KM, Hyland A, et al. Predictors of smoking cessation in a cohort of adult smokers followed for five years. Tob Control 1997;6(Suppl. 2):S57-62.

27. Ebbert JO, Hughes JR, West RJ, et al. Effect of varenicline on smoking cessation through smoking reduction: a randomized clinical trial. JAMA 2015;313:687-94. 